\title{
OXIDATIVE STATUS AND APOPTOSIS IN INFANTS AND CHILDREN WITH FEBRILE SEIZURE
}

\author{
$\mathscr{B} y$ \\ Samir M.Abou El Hassan, Mostafa M.El Ayouty, \\ Mona M.Hafez, Maydaa E.Zaki, Mayada S.El Husseini
}

From

Department of pediatric infectious diseases and malnutrition, Faculty of medicine, Mansoura University, Egypt.

\begin{abstract}
Objective : To assess the oxidative status and apoptosis in infants and children with febrile seizure. Methods: This study includes all children having a febrile seizure either simple or complex. They were 40 patients and tweenty children as control. Blood sample was taken from the patients to measure serum total anti-oxidant capacity, MDA, soluble Fas-L. Data was analyzed using SPSS 16. Results: We found that children with FS had significantly higher oxidative stress levels (higher MDA $33.41 \pm 10.36 \mathrm{nmol} / \mathrm{ml}$ and lower TAC median $=0.55 \mathrm{Mm} / \mathrm{L}) \quad(\mathrm{p} \leq 0.001)$ \& higher evidence of apoptosis at diagnosis (Median sFas-L $150 \mathrm{ng} / \mathrm{L}$ ) $(p=0.003)$ than control group. Conclusion: the present work provides evidence for the increase in
\end{abstract}

oxidative stress (higher MDA, lower TAC) and apoptosis (higher s Fas-L) when compared with control. Infection or fever per se may affect oxidative stress and apoptosis; which in their turn may cause and complicate FS. An inverse relationship between TAC and MDA leading to oxidative stress in FS. A correlation between oxidative stress and apoptosis.

Keywords : Febrile Seizure, Oxidative stress, Malondialdehyde, total antioxidant capacity, apoptosis.

Abbreviations : FS: Febrile seizure MDA: malondialdehyde ROS: reactive oxygen species $s F a s-$ $L$ : soluble fas ligand TAC: total antioxidant capacity TNF: tumor necrosis factor TNF-R: tumor necrosis factor receptor

MANSOURA MEDICAL JOURNAL 
168 OXIDATIVE STATUS AND APOPTOSIS IN INFANTS

INTRODUCTION

Febrile seizure is the most common cause of convulsion in infants and children (Karande, 2007); defined as convulsion occurring between 6 months and 5 years of age (mostly at 14-18 months) (Johnston, 2007), associated with fever without presence of intracranial infection or a cause for the seizure (Ganesh and Janakiraman; 2008).

Febrile seizures are divided into simple (85\% of febrile seizures) and complex/atypical types (Ganesh and Janakiraman; 2008).

Simple FS rarely affects the brain (Shinnar and Glauser, 2002). However, prolonged FS, may lead to mesial temporal sclerosis causing mesial temporal lobe epilepsy which is the most common cause of the refractory epilepsies (Engel, 2001).

The pathophysiology of FS is still largely unknown: The cytokines play important role in the generation of FS (Heida et al; 2009). Genetic factors may have a role (Sadleir and Scheffer, 2007), micronutrient deficiency, in addition to the effect of hyperthermia on neuronal excitability and chemical transmitters beside reactive oxygen free radicals (Gu"nes et al; 2009) \& apoptosis (Xu et al; 2007).

Febrile seizures diagnosis is clinically after exclusion of other causes of seizure, however; EEG \& neuroimaging are requested in certain conditions (McBride, 2012).

Oxidative stress is defined as unbalanced equilibrium between ROS, resulting from any normal or abnormal metabolic processes in the body, and the antioxidant defense mechanisms leading to biological damage of cellular lipids, proteins, DNA or Carbohydrates \& cell death (Fiore et al; 2005).

Free radicals are molecules containing one or more unpaired electrons in atomic orbitals (Halliwell and Gutteridge, 1999). Free radicals are extremely reactive, so they have a very short half-life.

Generation of ROS causes damage of polyunsaturated fatty acid residues of phospholipids, which are extremely sensitive to oxidation. The major aldehyde products of lipid peroxidation are: Malondialdehyde $\mathrm{Hy}$ - 
droxynonenal \& Isoprostanes (Stocker and Keaney, 2004).

Antioxidants may be enzymatic as superoxide dismutase and nonenzymatic antioxidants as Vitamin C \& Selenium (Valko et al., 2004).

For assessment of the oxidative stress status in vivo, researchers measure molecular products resulting from the reaction of ROS with biomolecules, which are generally considered more stable than ROS themselves, including lipid peroxidation end products as MDA, or antioxidant enzymes and molecules as superoxide dismutase, selenium, total antioxidant capacity (Dalle-Donne et al., 2006).

Oxidative stress has a very important role in FS, proved by Akarsu et al.; 2007 who found increased plasma \& erythrocytes malondialdehyde levels in children experiencing febrile seizures; in addition to elevation of plasma nitric oxide \& Glutathione peroxidase, however, decreased amounts of superoxide dismutase after febrile seizures due to its consumption. After recurrent or prolonged febrile seizures, the ultrastructure of specific organelles (mitochondria and endoplasmic reticulum) changes, and these changes lead to brain damage (Yang and Qin; 2004).

Neuronal vulnerability is an important factor for seizure-induced oxidative damage (Patel and Li; 2003).

In conclusion neuronal cell death may be both a cause and a consequence of seizures (Patel; 2002).

Apoptosis is a controlled \& mostly reversible process of programmed cell death that usually doesn't induce inflammatory reaction, it occurs through genetically defined \& sequential series of events that terminate cell survival by 'cellular suicide' which differentiate it from necrosis (Ziegler and Kung, 2008).

Apoptosis is an essential physiological process throughout the life important both in development and in the maintenance of tissue homeostasis (Testa, 2004). The defect in apoptosis can result in various pathological states, as malignant transformation and neurodegenerative diseases (Okada and Mark, 2004).

Apoptosis is controlled by numerMANSOURA MEDICAL JOURNAL 
ous proteins and protein complexes that when activated by various stimuli (initiator caspases), induce sequential activation of the effector caspases. There are at least 2 major pathways of caspase activation; the receptor-mediated (outer/extrinsic) apoptosis pathway where the TNF family of death receptors as TNF-R \& Fas, activate upstream caspase-8 (Hengartner, 2000). The TNF-R family proteins are characterized by the presence of cysteine-rich extracellular domains that mediate binding between ligands as (TNF- $\alpha$ \& Fas ligand) and these receptors (Ashkenazi and Dixit 1998).

The second pathway is the mitochondrial-mediated (intrinsic) apoptosis pathway where cytochrome C is released from the mitochondria and activates upstream caspase- 9 . Both pathways culminate in the activation of a major downstream effector caspase-caspase-3 (Hengartner, 2000). A third minor pathway of caspase activation involving granzyme B / perforin (Hengartner, 2000).

The most sensitive and surest way to detect apoptosis is the measurement of enzymes and proteins in- volved in the apoptotic process (Distelhorst and Shore; 2004).

$X u$ et al; 2007 studied the role of apoptosis in the genesis and epileptogenesis of MTS on a molecular level, through studying the expression of bcl-2, p53, fas and caspase-3 genes in resected sclerotic hippocampi from patients with refractory MTLE, which could be a process of the disease itself or may be induced by seizures. Ten of them had febrile convulsions in early childhood.

There is a great relation between apoptosis \& oxidative stress; the cellular redox environment plays an important role in signal transduction, enzyme activation, DNA and RNA synthesis, cell proliferation, differentiation and apoptosis (Moriai et al., 2001). Induction or inhibition of cell proliferation seems to be dependent on levels of oxidants/antioxidants in the cell. Apoptosis is induced by moderate oxidizing stimuli and antioxidant acting as defense mechanisms preventing apoptosis (Valko et al., 2006).

Oxidative stress following ischemia or seizures can cause severe endothelial cell injury (Lin et al; 
2006). Exposure of endothelial cells to TNF- $\alpha$ may result in endothelial dysfunction. TNF- $\alpha$ induce endothelial death through generation of ROS especially hydrogen peroxide and peroxynitrite (Corda et al; 2001).

\section{SUBJECTS AND METHODS}

This study includes all children who, within the preceding 6 hours, had experienced a febrile seizure either simple or complex, attending the outpatient clinic and emergency department of Mansoura University children's hospital \& fulfilling the inclusion criteria in the period from February 2011 to December 2012. They were 40 patients; whose ages ranging from 6 months to 5 years. Tweenty children of matched age, sex and socioeconomic status were included in the study as a control group, with no history of seizures or neurological disorders. Blood sample was taken from the patients to measure serum TAC, MDA, soluble Fas-L.

\section{STATISTICAL ANALYSIS}

Data was analyzed using SPSS 16; parametric data were expressed in mean \pm standard deviation. Non parametric data were expressed in median, minimum and maximum. Normality of data was first tested by one sample K-S test. In addition, Mann-Whitney was used to compare continuous variables in two different groups. Chi-square tests were used to compare the categorical variables between both cases and controls. $P$ value $<0.05$ was considered as statistically significant.

\section{RESULTS}

In our study, the median age of cases was 24.66 months, ranging from 5 \& 60 months. The Median age of control was 30 months, ranging from $9 \& 54$ months. There was male predominance in cases $(60 \%)$ $\&$ in control $(65 \%)$. There was no statistically significant difference between case and control group as regards age and sex.

We found that children with FS had significantly higher oxidative stress levels (higher MDA $33.41 \pm 10.36 \mathrm{nmol} / \mathrm{ml}$ and lower TAC median $=0.55 \mathrm{Mm} / \mathrm{L}) \quad(p \leq 0.001)$ \& higher evidence of apoptosis at diagnosis (Median sFas-L $150 \mathrm{ng} / \mathrm{L}$ ) $(p=0.003)$ than control group as shown in tables (1\&2). 
Table (1) Comparison of patients versus control as regards: basal serum sFas-L, TAC

\begin{tabular}{|l|c|c|c|}
\hline \multicolumn{1}{|c|}{ Variable } & Patients & Control & $\begin{array}{c}\text { Tests of } \\
\text { significance }\end{array}$ \\
\hline Serum sFas-L (ng/L) & $\mathrm{n}=40$ & $\mathrm{n}=20$ & $* 0.003$ \\
(Median) & 150 & 85 & \\
(minimum -Max) & $(30-780)$ & $(30-300)$ & \\
\hline $\begin{array}{l}\text { Serum TAC (Mm/L) } \\
\text { (Median) }\end{array}$ & 0.55 & 1.55 & $* 0.001$ \\
(minimum -Max) & $(0.1-1.9)$ & $(0.2-2.2)$ & \\
\hline
\end{tabular}

- $\quad p$ value is statistically significant if $<0.05$.

Table (2): Comparison of basal serum MDA levels between patients \& control:

\begin{tabular}{|c|c|c|c|}
\hline Variable & Patients & Control & $\begin{array}{c}\text { Tests of } \\
\text { significance }\end{array}$ \\
\hline $\begin{array}{c}\text { Serum } \\
\mathbf{M D A}(\mathbf{n m o l} / \mathbf{m l})\end{array}$ & & $\mathrm{n}=20$ & \\
Mean $\pm \mathrm{SD}$ & $33.41 \pm 10.36$ & $7.2 \pm 2.2$ & \\
& & & \\
\hline
\end{tabular}

* $\mathrm{p}$ value is statistically significant if $<0.05$.

Vol. 42, No. 1 \& 2 Jan. \& April, 2013 


\section{DISCUSSION}

In our study, we found children with FS had significantly higher oxidative stress (higher MDA and lower TAC) $(p \leq 0.001)$ than control. Similar finding was reported by Akarsu et al.; 2007 who found that plasma \& erythrocytes MDA increased in children with FS compared with the control group.

Tsai et al; 2010 stated that the role of MDA in the oxidative damage of seizures is uncertain.

Abuhandan et al; 2013 found that the total antioxidant status values of febrile seizure group were found to be statistically significant low compared to values of the control group.

Oxidative stress is considered a cause \& result of FS; fever per se changes tissue redox state through lipopolysaccharides, the primary element of bacterial cell wall, in addition to induction of proinflammatory cytokines, activated macrophages and other leukocytes to secrete reactive oxygen/nitrogen species (Hou et al; 2011). Also, hyperthermia-induced disruptions of mitochondrial oxidative phosphorylation and coupling may promote apoptosis not only by ag- gravating an energy stress, but also by increasing ROS production (Venkataraman et al., 2004).

The most important effect of oxidative stress is lipid peroxidation, leading to excess MDA (Stocker and Keaney, 2004), causing disruption and destruction of cell membrane lipids, proteins and DNA. Although the brain produces high amount of ROS, owing to high aerobic metabolism, it is very sensitive to oxidative injury (Naziroglu et al; 2008) due to its high polyunsaturated fatty acid content, poor repair capacity, and high iron load (Patel; 2002).

Elevated levels of free radicals and ROS can in turn exacerbate mitochondrial dysfunction, including inactivation of complex I (Riobo' et al., 2001). Free radicals can induce DNA damage that leads to apoptosis (White et al; 2007). Furthermore, inflammation response-associated hypoxia stimulated glutamate release, which caused excitotoxicity of cells by increasing extracellular $\mathrm{Ca} 2+$.

Seizure itself may cause oxidative stress as it elevates brain production of ROS (Tsai et al; 2010) in addition to deficiency of enzymatic and non-

MANSOURA MEDICAL JOURNAL 
enzymatic antioxidants leading to oxidative stress, causing damage cellular lipids, proteins or DNA, resulting in inhibition of their normal function (Valko et al., 2007).

In this study, higher evidence of apoptosis (increase sFas-L, used as apoptosis marker) was found in FS cases at diagnosis than control group $(p=0.003)$. Tan et al; 2001 found an increased Fas due to apoptosis in an epileptic animal model. Straussberg et al; 2001 stated that in children with histories of febrile convulsions, there was evidence of apoptosis (TNF- $\alpha$ levels in blood were steadily elevated) due to increased its production by the brain during sustained epileptic seizures in animal models. However, Lee et al; 1999 reported that no significant relationship was found between TNFalpha as a marker of apoptosis in children with febrile convulsions \& controls.

Apoptosis may be a cause or result of FS: Many theories explain apoptosis in FS through two pathways (Straussberg et al; 2001) especially intrinsic; relative hypoperfusion (Kreisman et al; 1991), pathological neuronal activity might also induce mitochondrial dysfunction and ROS production, chronic hypometabolism (Casse et al; 2002). Excessive heat exposure (Burattini et al., 2010).

ROS can produce DNA damage and strand breaks. In addition, topoisomerase I, an enzyme involved in DNA repair, is heat-sensitive and its inactivation could prevent correction of DNA damage (Ciavarra et al., 1992). DNA damage can lead to apoptosis by several mechanisms:

Excessive heat exposure or heat stress (high temperature especially more than $42{ }^{\circ} \mathrm{C}$ ) can induce irreversible heat damage such as necrosis, apoptosis of cells through intrinsic pathway (Burattini et al., 2010).

Fas-dependent apoptosis (extrinsic pathway) is involved in heatinduced apoptosis in neurons (Jayanthi et al., 2005).

The Fas receptor, a member of the tumor necrosis factor receptor family, recruits the FADD (Fasassociating protein with death domain) adapter molecule that binds procaspase-8, forming the deathinducing signaling complex (DISC), releasing neurotransmitters as gluta- 
mate and glycine in CSF. While associated with the DISC, procaspase8 and/or procaspase-10 is cleaved into its activated form, initiating a proteolytic cascade resulting in caspase-3 activation, death and hyperexcitability (White et al; 2007). In addition of other Caspase-independent pathways.

FS may cause apoptosis and further brain damage. One of the most important complication of febrile seizure is MTS leading to MTLE; MTS is characterized by neuronal loss and gliosis. Theoretically, two cellular mechanisms contribute to neural loss in MTS; necrosis and apoptosis (Ananth et al; 2001).

$X u$ et al; 2007 stated that there was evidence of apoptosis found in the sclerotic hippocampus of patients with drug-resistant MTLE associated with MTS compared with control (through increased expression of bcl-2, p53, Fas and caspase3 ); which could be a process of the disease itself or may be induced by seizures.

In our study, there was significant $\mathrm{t}$ negative correlation between MDA \& TAC in cases, there was insignifi- cant positive correlation between MDA and Fas; and insignificant negative correlation between TAC and Fas

\section{CONCLUSION}

In conclusion, the present work provides evidence for the increase in oxidative stress (higher MDA, lower TAC) and apoptosis (higher s Fas-L) when compared with control. Infection or fever per se may affect oxidative stress and apoptosis; which in their turn may cause and complicate FS. An inverse relationship between TAC and MDA leading to oxidative stress in FS. A correlation between oxidative stress and apoptosis.

\section{REFERENCES}

1) Akarsu $S$, Yilmaz $S$, Ozan $S$, Kurt A, Benzer F, and Gurgoze MK. (2007) : Effects of Febrile and Afebrile Seizures on Oxidant State in Children. Pediatric Neurology 2007; 36 (5), 307311.DOI:10.1016/j. pediatrneurol.01.010

2) Ananth C, Dheen TS, Gopalakrishnakone $P$, et al. (2001) : Domoic acidinduced neuronal damage

MANSOURA MEDICAL JOURNAL 
in the hippocampus: changes in apoptosis related genes (bcl-2, bax, caspase-3) and microglial response. Journal of Neuroscience Research 2001; 66(2): 177-190. DOI: 10.1002/jnr.1210 (Accessed 28 Sep).

3) Ashkenazi A and Herbst RS. (2008) : To kill a tumor cell: the potential of proapoptotic receptor agonists. J Clin Invest 2008; 118: 19791990.

4) Burattini S, Battistelli M, Falcieri E. (2010) : Morphofunctional features of invitro cell death induced by physical agents. Current Pharmaceutical Design; 16 (12), 1376-1386. DOI: $10.2174 /$

138161210791033941.

5) Casse R, Rowe CC, Newton M, Berlangieri SU, Scott AM. (2002) : Positron emission tomography and epilepsy. Molecular Imaging and Biology; 4 (5), 338-351.

Vol. 42, No. 1 \& 2 Jan. \& April, 2013
6) Ciavarra RP, Duvall Wand Castora FJ . (1992) : Induction of thermotolerance in $T$ cells protects nuclear DNA topoisomerase I from heat stress. Biochem. Biophys. Res. Commun. 186: 166-172.

7) Corda S, Laplace C, Vicaut E, Duranteau J. (2001) : Rapid reactive oxygen species production by mitochondria in endothelial cells exposed to tumor necrosis factor-alpha is mediated by ceramide. American Journal of Respiratory Cell and Molecular Biology; 24(6): 762-768. DOI: 10.1165/ ajrcmb.24.6.4228. (Accessed 1-Feb-2003).

8) Dalle-Donne I, Scaloni A, Giustarini D, Cavarra E, Tell G, Lungarella $G$, et al. (2005) : Proteins as biomarkers of oxidative/ nitrosative stress in diseases: the contribution of redox proteomics. Mass Spectrometry Reviews; 24 (1): 55-99. DOI: 10.1002/ mas.20006 (Accessed 6 Apr 2004). 
9) Distelhorst CW, Shore GC. (2004) : Bcl-2 and calcium: controversy beneath the surface. Oncogene; 23: 2875-2880. DOI: 10.1038/ sj.onc. 1207519

10) Engel J. (2001) : Mesial temporal lobe epilepsy: what have we learned? Neuroscientist; 7 (4), 340-352. DOI:

$10.1177 /$ 107385840100700410

11) Fiore G, Florio P, Micheli $L$, Nencini C, Rossy M, Cerretani $D$ et al. (2005) : Endothelin-1 triggers placental oxidative stress pathways: putative role in preeclampsia. The Journal of Clinical Endocrinology and Metabolism; 90 (7), 4205-4210. DOI: 10.1210/ jc.2004-1632 (Accessed 19 April 2005).

12) Ganesh $R$, Janakiraman $L$. (2008) : Serum Zinc Levels in Children with simple febrile seizure. Clinical Pediatrics; 47 (2), 164-166. DOI: $\quad 10.1177 /$ 0009922807306165 (AC- cessed 14 Sep 2007)

13) Günex S, Dirik E, Yisx U, $\mathrm{Sec}_{3}$ kin $E$, Kuralay $F$, Ko"se S, et al. (2009) : Oxidant status in children after febrile seizures. Pediatric Neurology; 40 (1), 4749. DOI: 10.1016/ j.pediatrneurol. (Accessed 6 Sep 2008).

14) Halliwell B, Gutteridge JMC. (1999) : Oxidative stress and antioxidant protection: some special cases. In: Halliwell B, Gutteridge JMC, editors. Free Radicals in Biology and Medicine. 3rd ed. Oxford: Clarendon Press;. p530-533.

15) Heida JG, Moshe' SL, Pittman QJ. (2009) : The role of interleukin-1b in febrile seizures. Brain and Development; 31 (5), 388-393. DOI: 10.1016/j.braindev. 2008.11.013 (Accessed 13 Feb 2009).

16) Hengartner MO. (2000) : The biochemistry of apoptosis. Nature 2000; 407 (6805): MANSOURA MEDICAL JOURNAL 
770-776. DOI: 10.1038/ 35037710 .

17) Hou C, Lin H, Chang C, Huang W, Lin M. (2011) : Oxidative stress and pyrogenic fever pathogenesis. European Journal of Pharmacology; 667: 6-12. DOI:10.1016/ j.ejphar.2011.05.075 (Accessed 7 June 2011).

18) Jayanthi $S$, Deng $X$, Ladenheim B, McCoy MT, Cluster A, Cai NS et al. (2005) : $\quad$ Calcineurin/NFATinduced up-regulation of the Fas ligand/Fas death pathway is involved in methamphetamine-induced neuronal apoptosis. Proc. Natl. Acad. Sci. U.S.A.; 102: 868-873.

19) Johnston M. (2007) : Febrile seizure. In: Behrman RE, editor. Nelson textbook of pediatrics. 18th ed. Philadelphia: Saunders; 2457-8.

20) Karande S. (2007) : Febrile seizures: A review for family physicians. Indian $\mathrm{J}$ Med
Sci.; 61 (3): 161-70.

21) Kreisman NR, Magee JC, Brizzee BL. (1991) : Relative hypoperfusion in rat cerebral cortex during recurrent seizures. J Cereb Blood Flow Metab; 11, 77-87.

22) Lee JS, Park SH, Coe CJ, Kim SH. (1999) : Pathogenesis and Correlations of Serum and Cerebrospinal Fluid Zinc Levels in Febrile Convulsions. Journal of Korean child neurology society. Dec; 7(2):205-213.

23) Lin R, Liu J, Peng N, Gan W, Wang W, Han C, et al. (2006) : Lovastatin reduces apoptosis and downregulates the CD40 expression induced by TNF-alpha in cerebral vascular endothelial cells. Curr Neurovasc Res; 3: 41-47.

24) McBride MC. (2012) : FS: neurological disorders in children: Merck manual professional.

25) Moriai R, Asanuma K, Kobaya- 
shi D, Yajima T, Yagihashi A, Yamada $M$, et al. (2001) : Quantitative analysis of the the anti-apoptotic gene survivin expression in malignant haematopoietic cells. Anticancer Res; 21: 595-600.

26) Naziroglu $M$, Kutluhan $S$ and Yilmaz M. (2008) : Selenium and topiramate modulates brain microsomal oxidative stress values, $\mathrm{Ca}+-$ ATPase activity, and EEG records in pentylenetetrazol-induced seizures in rats. J Membr Biol; 225, 39-49.

27) Okada $\mathrm{H}$ and Mark TW. (2004) : Pathways of apoptotic and non-apoptotic death in tumour cells. Nat Rev Cancer; 4: 592-603.

28) Patel M and Li QY. (2003) : Age dependence of seizureinduced oxidative stress. Neuroscience;

118 , 431-437.

29) Patel MN. (2002) : Oxidative stress, mitochondrial dys- function, and epilepsy. Free Radi c Res; 36, 1139-46.

30) Riobo' NA, Clementi E, Melani M, Boveris A, Cadenas E, Moncada $S$ et al. (2001) : Nitric oxide inhibits mitochondrial NADH: ubiquinone reductase activity through peroxynitrite formation. Biochem. J. 2001; 359: 139-145.

31) Sadleir LG and Scheffer IE. (2007) : Febrile seizures. BMJ; 334, 307-311.

32) Shinnar $S$ and Glauser TA. (2002) : Febrile seizures. Child Neurol.; 17 (Suppl. 1), S44-S52.

33) Stocker R, Keaney JF. (2004) : Role of oxidative modifications in atherosclerosis. Physiol Rev; 84:13811478.

34) Straussberg R, Amir J, Harel L, Punsky I, and Bessler $\mathrm{H}$. (2001) : Pro- and anti- inflammatory cytokines in children with febrile convulMANSOURA MEDICAL JOURNAL 
sions. Pediatric Neurology;

24(1): 49-53. DOI:

10.1016/S0887-8994

(00)00234-4 (Accessed on JAN 2001).

35) Tan Z, Levid J, Schreiber SS. (2001) : Increased expression of Fas(CD95/ APO-1) in adult rat brain after kainate-induced seizures. Neuroreport; 12:1979-82.

36) Testa U. (2004) : Apoptotic mechanisms in the control of erythropoiesis. Leukemia; 18:1176-1199.

37) Tsai $H$, Chang $C$ and Chang $S$. (2010) : The effects of pilocarpine-induced status epilepticus on oxidative stress/damage in developing animals. Brain \& Development; 32, 25-31.

38) Valko M, Izakovic M, Mazur M, Rhodes $\mathbf{C J}$ and Telser $\mathbf{J}$. (2004) : Role of oxygen radicals in DNA damage and cancer incidence. Mol Cell Biochem; 266: 37-56.

39) Valko M, Leibfritz D, Moncol J,
Cronin MT, Mazur M, Telser J. (2007) : Free radicals and antioxidants in normal physiological functions and human disease. Int J Biochem Cell Biol 2007; 39:44-84.

40) Valko M, Rhodes CJ, Moncol J, Izakovic $\mathbf{M}$, Mazur $\mathbf{M}$. (2006) : Free radicals, metals and antioxidants in oxidative stress-induced cancer. Chem Biol Interact; 60:1-40.

41) Venkataraman $S$, Wagner $B A$, Jiang $X$, Wang HP, Schafer FQ, Ritchie JM, et al. (2004) : Overexpression of manganese superoxide dismutase promotes the survival of prostate cancer cells exposed to hyperthermia. Free Radic. Res.; 38: 1119-1132.

42) White MG, Luca LE, Nonner D, Saleh O, Hu B, Barrett EF, et al. (2007) : Cellular mechanisms of neuronal damage from hyperthermia. In: Sharma HS, editor. Progress in Brain 
Research; 162 chapter 17. p 347-371. DOI:

$10.1016 / \mathrm{S} 0079-6123$

(06)62017-7.

43) Xu S, Pang Q, Liu Y, Shang W, Zhai G, Ge M. (2007) : Neuronal apoptosis in the resected sclerotic hippocampus in patients with mesial temporal lobe epilepsy. Journal of Clinical Neuroscience 2007; 14 (9): 835-840.
44) Yang ZX, Qin J. (2004) : Interaction between endogenous nitric oxide and carbon monoxide in the pathogenesis of recurrent febrile seizures. Biochem Biophys Res Commun 2004; 315, 349-55.

45) Ziegler DS, Kung AL. (2008) : Therapeutic targeting of apoptosis pathways in cancer. Curr Opin Oncol; 20: 97-103. 